\title{
Perancangan Alat Proses Distilasi Air Laut menggunakan Pemanas Elektrik
}

\author{
Bayu Buana Taqwa ${ }^{1}$, Rosalina ${ }^{2}$, Harry $\operatorname{Ramza}^{3}$ \\ ${ }^{1,2,3}$ Program Studi Teknik Elektro, Fakultas Teknik \\ Universitas Muhammadiyah Prof. Dr. HAMKA \\ Jalan Tanah Merdeka No 6, Kp Rambutan, Jakarta 13830, INDONESIA \\ Telp : +62-21-8400341, Faks : +62-21-8411531 \\ E-mail : bayubuana163@gmail.com,rosalina@uhamka.ac.id,hramza@uhamka.ac.id \\ * Penulis Koresponden
}

\begin{abstract}
Abstrak -Penelitian ini bertujuan untuk mengetahui kualitas hasil air proses distilasi air laut, berapa banyak volume air yang di keluarkan jika suhu dan input voume air yang penulis inginkan, dan berapa lama waktu proses distilasi air laut dengan perbandingan input air laut dan ketetapan suhu yang telah ditetapkan.Masih banyak masyarakat indonesia yang ada di pesisir pantai kekurangan air bersih. Inovasi teknologi yang diperlukan untuk upaya penyediaan air bersih pada masyarakat di sekitar pesisir pantai. Proses distilasi tersebut memerlukan teknologi untuk keefektifan dalam memperoleh air bersih dalam penyediaan air bersih. Tabung evaporator menggunakan pemanas elektrik agar efektif dalam perebusan air laut di dalam tabung evaporator, dan juga di dalam tabung evaporator terdapat sensor suhu yang berfungsi memantau suhu pada tabung evaporator yang mana suhu pada tabung evaporator akan dijaga oleh Arduino dan terhubung ke relay dengan cara memutus dan menghubungkan tegangan yang tersambung ke pemanas elektrik. Hasil percobaan menunujukan jika input 5 liter air laut dengan ketetapan suhu $102.00^{\circ} \mathrm{C}$ menghasilkan $600 \mathrm{ml}$ dengan waktu 5 jam 5 menit dan Jika input 5 liter air laut dengan ketetapan suhu $92.00^{\circ} \mathrm{C}$ menghasilkan $200 \mathrm{ml}$ dengan waktu 15 jam 7 menit. Kadar air hasil porses distilasi air laut memiliki ph air 7,4 dan kadar 16 ppm, yang berarti air dari hasil proses distilasi layak dikonsumsi sehari hari.
\end{abstract}

Kata kunci : Distilasi 1, tenaga surya 2, kata kunci 3.

\section{LATAR BELAKANG}

Standar air bersih juga harus diperhatikan oleh masyarakat indonesia agar masyarakat indonesia terhindar dari gangguan kesehatan. Secara syarat fisika standar air bersih perlu memenuhi beberapa yaitu air tidak disebabkan butiran koloid tanah liat atau jernih alias tidak keruh, tidak mengandung zat-zat berbahaya pada kesehatan dan tidak berwarna pada air, tidak memiliki rasa asin, manis atau pahit dan hanya memilki rasa tawar, tidak berbau karena adanya penguraian bahan organik oleh mikroorganisme air.

Beberapa syarat kimia yang harus juga di perhatikan oleh masyarakat yaitu kandungan $\mathrm{PH}$ (derajat keasaman) mencapai 6-8 yang mana jika lebih atau kurang senyawa kimia berubah menjadi racun yang menganggu kesehatan, tidak mengandung besi $(\mathrm{Fe})$ lebih dari $0,1 \mathrm{mg}$ dimana dapat dicirikan dengan air yang cenderung warna kuning dan rasa pada air tersebut tidak tawar yang mana dapat menggangu kesehatan pada tubuh, pencemaran timbal $(\mathrm{Pb})$ berasal dari logam yang akan menyebabkan gangguan ginjal, hati, dll.

Proses distilasi air laut berlangsung dengan cara merebus air agar air tersebut berubah menjadi uap, yang mana akan terjadi perubahan wujud menjadi air tawar.
Salah satu cara agar merubah air laut menjadi air tawar adalah proses perbusan air. Proses merebus air laut tersebut di rebus dalam tabung yang bernama tabung evaporator. Suhu pada tabung evaporator dipantau oleh sensor termokopel dan data pada sensor suhu termokopel dikirm ke Arduino dan di proses oleh Arduino dan data akan dikirim ke relay, relay akan memutus atau menghubungkan tegangan.

Pada penelitian (ERFAN, 2017) yang berjudul "Rancang Bangun Destilator Air Laut Tenaga Surya Menggunakan Penyerap Tipe Bergelombang Berbentuk Limas", tujuan dari penelitian ini adalah untuk mengetahui pengaruh destilator air laut tenaga radiasi panas matahari menggunakan penyerap tipe bergelombang berbentuk limas terhadap kuantitas air tawar yang dihasilkan dan mengetahui kualitas air tawar hasil destilator.

\section{DASAR TEORI}

\subsection{Evaporasi}

Evaporasi adalah proses kebalikan dari kondensasi, (contohnya air) dengan spontan menjadi gas (contohnya 
B. B. Taqwa ${ }^{1}$, R. Rosalina ${ }^{2}$, H. Ramza ${ }^{3}$

uap air) (Azis \& Fajaryati, 2018). Dapat dikatakan evaporasi adalah proses perubahan molekul didalam keadaan cair. Terjadinya evaporasi ketika tingkat kelembaban lebih rendah daipada tingkat penguapan. Proses evaporasi terjadi pada alam, contohnya air yang ada di danau, sungai, laut dan lain-lain menguap dan berkumpul pada atmosfer. Contoh lain dari evaporasi ketika tubuh kita sedang melakukan aktifitas yang berat atau tubuh kita sedang berada di daerah yang panas maka tubuh kita mengeluarkan cairan yang biasa kita sebut keringat, keringat pada tubuh kita menerima energi panas dari luar tubuh dan dalam tubuh kita tingkat kelembabannya rendah selanjutnya kita melakukan proses pendinginan dan akhirnya tubuh kita mengeluarkan keringat.

Faktor yang mempengaruhi proses evaporasi yaitu

a) Tekanan udara

Tekanan udara adalah tenaga yang bekerja untuk menggerakan massa udara dalam setiap satuan luas tertentu. Semakin tinggi tempat atau ruangan semakin rendah tekanaan udaranya karena tekanan udara akan berbanding terbalik dengan ketinggian suatu tempat. Kenaikan tekanan sebanding dengan kenaikan titik didih. Tekanan dapat dibuat vacum untuk menurunkan titik didih cairan sehingga proses penguapan lebih cepat.

b) Luas permukaan

Cepat atau lambat proses evaporasi dikarenakan luas permukaan pada proses evaporasi. Semakin luas permukaan bidang kontak antara pemanas dengan cairan, maka semakin banyak molekul air yang teruapkan dan semakin cepat prsoes penguapan.

\section{c) Temperatur suhu}

Pada proses evaporasi temperatur suhu sangat mempengaruhi hasil pada proses penguapan. Besar kecilnya kemampuan udara menyerap air dikarenakan tinggi rendahnya suhu pada permukaan bidang. Energi kinetik molekul air meningkat jika suhu suhu pada permukaan tinggi, sehingga molekul air semakin banyak yang berpindah ke lapis udara di atasnya dalam bentuk uap air.

\subsection{Perpindahan Panas}

Akibat adanya perbedaan temperatur maka energi kalor atau panas akan berpindah, proses tersebut dapat dikatakan proses perpindahan panas.energi kalor akan berpindah dari temperatur media yang paling tinggi ke temperatur yang lebih rendah. Perubahan suhu dapat terjadi pada Hambatan listrik dan materi zat,warna pada benda dapat dipancarkan terjadi pada suhu tinggi. Contohnya jika kita perhatikan, pemanas elektrik pada kompor listrik yang memancarkan warna merah ketika panas (Idawati Supu, Baso Usman, Selviani Basri, 2016) Terjadinya proses perpindahan panas dapat terjadi secara radiasi, konduksi, dan konveksi.

\section{a. Radiasi}

Perpindahan panas secara radiasi adalah perpindahan panas atau kalor yang tidak membutuhkan zat perantara. Contoh dari radiasi adalah ketika dekat dengan api yang menyala tubuh kita merasakan hangat, contoh lain dari radiasi adalah matahari yang memancarkan panas ke bumi yang langsung kita rasakan. Pada perpindahan panas radiasi, radiasi panas atau kalor yang diserap atau di pancarkan tergantung dari warna benda tersebut. Penyerap dan pemancar kalor atau panas yang baik adalah warna- warna gelap, sementara itu warna-warna terang penyerap dan pemancar yang buruk kalor atau panas.

$$
q=e \times \sigma \times A \times \Delta T^{4}
$$

$q=$ laju perpindahan panas $($ Watt $)$

$e=$ emisifitas konveksi material

$\sigma=$ konstanta Blotzmann $\left(5,67 \times 10^{-8} \mathrm{Watt} / \mathrm{m}^{2} \mathrm{~K}^{4}\right)$

\section{b. Konduksi}

Konduksi adalah peristiwa perpindahan panas atau kalor tanpa di sertai perpindahan zat perantara yang melalui zat perantara. Pada umumnya perpindahan panas atau kalor secara konduksi terjadi pada benda-benda padat seperti logam. Dalam kehidupan sehari-hari, contoh dari perpindahan panas atau kalor secara konduksi ini ketika memasak air pada panic yang mana kalor atau panas berpindah dari api kompor menuju panci dan panas atau kalor merambat di selutuh dinding panci yang menyebabkan air mendidih.

$$
q=-k \times A \times\left(\frac{\Delta T}{\Delta x}\right)
$$

$$
\begin{aligned}
& q=\text { laju perpindahan panas }(\text { Watt }) \\
& -k=\text { konduktivitas panas }(\mathrm{W} / m K) \\
& A \quad=\text { luas perpindahan panas }\left(\mathrm{m}^{2}\right) \\
& \Delta T \quad=\text { perbedaan temperatur }(K) \\
& \Delta x \quad=\operatorname{jarak}(m)
\end{aligned}
$$

\section{c. Konveksi}

Konveksi adalah perpindahan panas atau kalor yang disertai dengan zat perantaranya. Proses perpindahan panas secara kalor ini hampir sedikit mirip dengan konduksi, yang membuat dua hal proses itu berbeda adalah zat perantaranya. Contoh dari proses konveksi di dalam kehidupan sehari-hari adalah ketika memasak air pada api kompor, maka air bagian bawah akan lebih dulu panas. Terjadinya perubahan massa jenis air menyebabkan air yang di bawah panas akan bergerak ke atas sedangkan air yang di atas akan bergerak ke bawah, dan begitu seterusnya yang mengakibatkan keseluruhan suh air menjadi sama.

$$
q=h \times A \times \Delta T^{4}
$$

$q \quad=$ laju perpindahan panas (Watt)

$h \quad=$ koefisien konveksi material $\left(W / m^{2} K\right)$

$A \quad=$ luas penampang permukaan $\mathrm{m}^{2}$

$\Delta T \quad=$ perbedaan temperatur $(K)$

\subsection{Arduino}

Arduino dirancang untuk memudahkan penggunaan elektronik dalam berbagai bidang yang mana fungsi dari arduino adalah pengendali mikro single-board yang bersifat sumber terbuka, diturunkan dari Wiring platform. Perangkat kerasnya dari arduino memiliki softwarenya memiliki bahasa pemrograman sendiri dan memiliki prosesor AtmelAVR. 
Para pemula dapat dengan mudah belajar mikrokontroler dengan arduino karena Arduino didesain agar mudah untuk dipelajari dan pemograman arduino tidak sebanyak tahapan mikrokontroller konvensional (JauhariArifin, Leni Natalia Zulita, 2016). Arduino dikatakan sebagai sebuah platform dari physical computing yang bersifat open source. Arduino adalah kombinasi dari hardware yang bukan hanya sekedar sebuah alat pengembangan. Arduino uno mempunyai aplikasi (Integrated Development Environment) IDE yang berguna untuk membuka, membuat dan mengedit source code Arduino. Berikut adalah gambar dari Arduino uno.

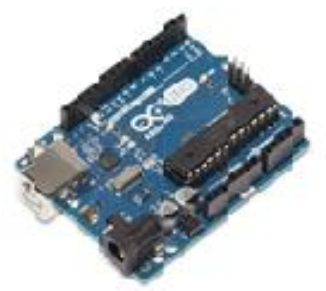

Gambar 1. Arduino

\subsection{Sensor Suhu}

Sensor suhu berfungsi mendeteksi gejala perubahan suhu pada objek tertentu, karena sensor ini dapat mengubah besaran panas menjadi besaran listrik.Contoh peralatan sehari-hari yang menggunakan sensor suhu ruangan yaitu rice cooker, air conditioner, thermometer suhu badan dan lain-lain.

Jenis sensor suhu yang dipakai dalam penelitian alat ini adalah sensor suhu jenis termokopel. Termokopel (Thermocouple) mempunyai kapasitas rentang suhu yaitu berkisar $-200^{\circ} \mathrm{C}$ hingga lebih besar dari $2000^{\circ} \mathrm{C}$ dengan harga yang relatif rendah menjadi salah satu jenis sensor suhu yang paling sering digunakan.

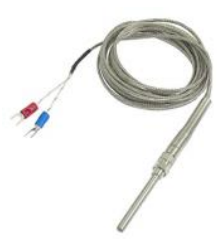

Gambar 2 Sensor Termokopel

Sensor suhu ini akan mendeteksi suhu pada tabung agar mendeteksi suhu pada tabung yang mana hasil deteksi suhu pada tabung akan memberi informasi suhu pada pengguna.

\subsection{Driver Max}

Driver max 6675 befungsi mengubah sinyal dari analog ke digital dengan memasukan data 12-bit. Driver max 6675 juga berfungsi mengurangi gangguan sinyal atau noise yang masuk bersamaan dengan input bersama termokopel. Kelebihan max 6675 ini mampu membaca suhu dari yang terendah $0,25^{\circ} \mathrm{C}$, dan pembacaan suhu $\pm 1024^{\circ} \mathrm{C}$, akurasi termokopel 8 LBS untuk suhu mulai dari $0{ }^{\circ} \mathrm{C}$ hingga \pm $700^{\circ} \mathrm{C}$ (Bachtiar ilman mochamad, 2018).

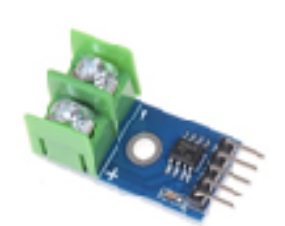

Gambar 3 Driver Max 6675

Pada driver max 6675 juga sudah terdapat pengkondisi sinyal untuk mengubah sinyal dari termokopel menjadi tegangan yang sesuai dengan kriteria dari input channel dari ADC. Masukkan dari T+ dan T- terhubung ke rangkaian.

\section{$2.6 \mathrm{pH}$ (Power of Hydrogen)}

pH (Power of Hydrogen) satuan keasamaan untuk menyatakan tingkat kebasaan atau keasaman yang dimiliki oleh suatu larutan, zat dan benda. nilai 6.5 hingga 7.5 adalah nilai $\mathrm{pH}$ yang memliki nilai normal, jika zat tersebut memiliki sifat asam berarti memiliki nilai $\mathrm{pH}<6.5$ dan jika zat tersebut bersifat basa maka bernilai $\mathrm{pH}>7.5$ (Zulfian Azmi, Saniman, 2016).

Air murni bersifat netral ditetapkan sebagai 7,0, sehingga larutan yang kurang dari sesuai ketetapan yaitu 7,0 disebut berifat asam. Pengukuran $\mathrm{pH}$ sangat penting dalam menentukan tingkat derajat keasaman air setelah terjadinya proses distilasi air laut.

PH meter adalah jenis alat ukur yang berfungsi untuk mengukur kebasaan suatu cairan atau tingkat keasaman air. Bila $\mathrm{pH}$ air mencapai $>7$ maka larutan air tesebut bersifat basa dan jika $\mathrm{pH}$ air tersebut mencapai $<7$ maka larutan tersebut bersifat asam dalam larutan netral $\mathrm{pH}=7$.

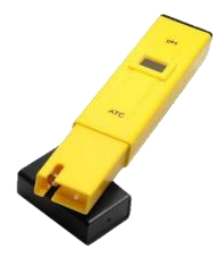

Gambar 4 TDS Meter

Terdapat elektroda khusus yang berfungsi untuk mengukur $\mathrm{pH}$. Bahan-bahan semi padat pada $\mathrm{pH}$ meter digital, elektroda atau probe pengukur terhubung alat elektronik yang akan menampilkan nilai $\mathrm{pH}$. Bagian terpenting dari $\mathrm{pH}$ meter adalah probe atau elektroda, yang bentuknya seperti batang dan terbuat dari kaca. Terdapat bohlam di bagian bawah elektroda yang merupakan bagian sensitif dari probe dan berisi sensor.

\subsection{PPM( Parts Per Million)}

Pecahan yang sangat kecil memiliki satuan-satuannya dipakai sebagai satuan nirdimensi, satuan ini disebut PPM (Parts Per Million).

Semakin dikit partikel pada cairan, semakin bagus untuk dikonsums sehari hari. Deteksi TDS pada air dengan menggunakan alat TDS scan yang berupa stik yang bekerja secara otomatis dan mampu menunjukkan jumlah polutan didalam air (Khairunnas \& Gusman, 2018). 
Tabel 1. Kategori Kandungan ppm

\begin{tabular}{cc}
\hline Kadar ppm & Tingkatan penilaian \\
\hline$<300$ & Sangat bagus \\
$300-600$ & Bagus \\
$600-900$ & sedang \\
$900-1.200$ & Buruk \\
$>1.200$ & Berbahaya \\
\hline
\end{tabular}

\subsection{Elemen Pemanas}

Elemen panas adalah suatu perangkat yang dapat mengubah energi listrik menjadi energi panas dengan melalui proses joule heating.Pada penelitian ini, penulis menggunakan element panas jenis coil heater. Bentuk dari coil heater adalah tidak tertutup atau terbuka dari isolator ataupun pipa selongsong yang cocok untuk memanaskan udara di sekitar.

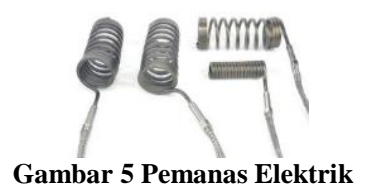

Coil Heater didukung dengan gagang pemegang yang berbahan isolator yang baik dan tahan panas yang tinggi, bahan tersebut diantaranya yaitu mika, keramik, asbes, castable, dan lain-lain.

\subsection{Relay}

Relay merupakan komponen Electromechanical (Elektromekanikal) yang terdiri dari 2 bagian utama yakni Mekanikal (seperangkat Kontak Saklar/Switch) dan Elektromagnet (Coil) dan berfungsi sebagai saklar (switch) yang di operasikan secara listrik. Relay menggerakkan Kontak Saklar menggunakan Prinsip Elektromagnetik sehingga dengan arus listrik yang kecil (low power) dapat menghantarkan listrik yang bertegangan lebih tinggi (Saleh \& Haryanti, 2017).

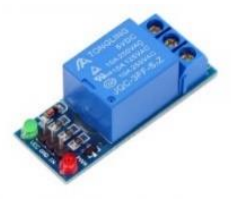

Gambar 6. Relay

Relay sering di aplikasikan ke dalam peralatan elektronika contohnya digunakan untuk menjalankan fungsi logika (Logic Function), untuk mengendalikan sirkuit tegangan tinggi dengan bantuan dari signal tegangan rendah dan untuk memberikan fungsi penundaan waktu (Time Delay Function).

\subsection{Water Level}

Resistor berfungsi untuk membatasi atau menghambat aliran listrik dalam suatu rangkaian. Sesuai dengan namanya, resistor bersifat resistif yang mana salah satu termasuk dalam komponen pasif.

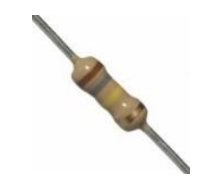

Gambar 7 Resistor

Level artinya ketinggian, sedangkan switch artinya saklar, jadi secara keseluruhan berarti saklar otomatis yang digunakan untuk mendeteksi ketinggian, contohnya digunakan untuk mendeteksi suatu volume benda cair yang terdapat pada suatu tabung atau tangki penampungan seperti tangki air. Pada penelitian ini, Sensor level yang digunakan menggunakan resistor, cara kerja dari sensor level yang menggunakan resistor yaitu level switch dipasang pada tangki air untuk mendeteksi jumlah atau volume air yang masuk kedalam tangki, kemudian alat ini dihubungkan dengan mesin pompa air, pada saat volume air didalam tabung sudah mencapai level tertentu (high 10 misalkan) dan terdeteksi oleh sensor, maka sensor level switch akan mengirim data ke arduino untuk di tampilkan data volume ke LCD.

\section{PERANCANGAN SISTEM}

\subsection{Kerangka Perancangan}

Dalam melakukan suatu perancangan memiliki langkah dan proses yang digunakan. Proses dan langkah-langkah perancangan dalam penelitian ini dapat dilihat pada gambar di bawah ini :

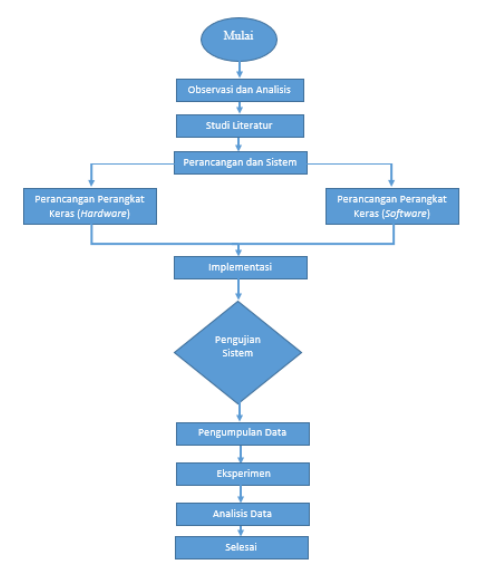

Gambar 8 Blok Diagram

\subsection{Perangkat Keras Hardware}

Pada kebutuhan perangkat keras ini akan di bahas kebutuhan perangkat keras yang ada dalam penelitian ini.

a. Arduino Uno

b. Sensor suhu (Thermocouple)

c. Relay

d. Water Level

e. Sensor Ph meter

f. Pemanas elektrik (Heater)

g. LCD

h. Driver Max 6675 
i. Kabel jumper untuk menghubungkan antara pin ke pin

j. Tabung evaporator

k. Tabung air bersih

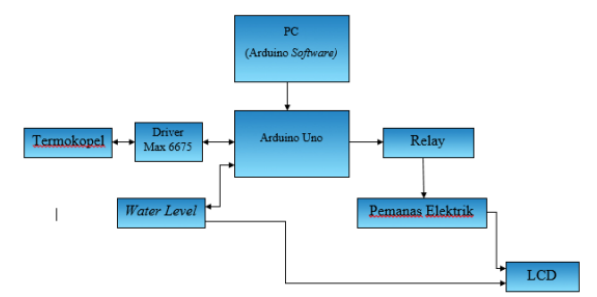

Gambar 9 Blok Diagram Perangkat Keras Hardware

\subsection{Perangkat lunak (Software)}

Perangkat lunak Arduino Ide adalah istilah untuk data yang disimpan secara digital termasuk program komputer. Arduino berfungsi sebagai text editor untuk membuat, mengedit, memvalidasi kode, dan juga membuka kode untuk di unggah ke board mikrokontroler. Berikut adalah gambar blok diagram perangkat lunak (software).

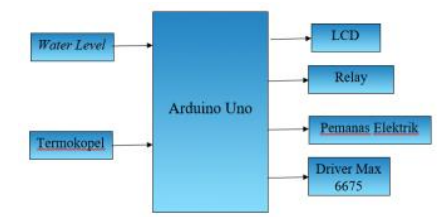

Gambar 10 Blok Diagram Perangkat Lunak (Software)

\subsection{Blok Diagram Perancangan Sistem}

Dalam penelitian ini penulis menggunakan langkah diagram blok untuk menganalisa penilitan. Blok diagram dapat dilihat pada gambar di bawah ini.

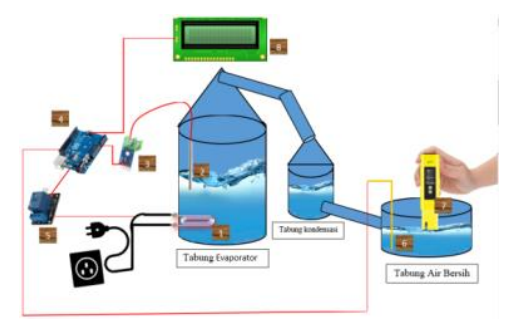

Gambar 11 Blok Diagram Perancangan Sistem.

Keterangan perangkat-perangkat di atas adalah sebagai berikut :

1. Pemanas elektrik (Heater)

2. Sensor suhu (Thermocouple)

3. Driver Max 6675

4. Arduino Uno

5. Relay

6. Water Level

7. Sensor $\mathrm{pH}$ meter atau ppm meter

8. LCD
Pada gambar 4.3 di atas terdapat dua tabung yang mempunyai perancangan berbeda karena terdapat perangkat yang sedikit berbeda. Dalam perancangan ini penulis membagi dua bagian yaitu, perancangan tabung evaporator dan perancagan tabung air bersih.

\subsection{Perancangan Tabung Evaporator}

Pada perancangan tabung evaporator berguna untuk menampung proses air yang juga tempat proses penguapan atau proses mendidih dari air laut itu sendiri. Tabung evaporator disertai dengan elemen pemanas, dan sensor suhu. Sensor suhu (termokopel) berfungsi memantau suhu pada tabung evaporator, dimana data suhu pada tabung evaporator akan dikirim ke Arduino melewati driver max 6675 yang berfungsi mengubah sinyal dari analog ke digital dan data yang di peroleh dari sensor suhu (termokopel) melalui diriver max 6675 dan Arduino tersebut akan di kontrol dengan relay sesuai dengan suhu yang ditentukan. Relay memutuskan tegangan jika suhu pada tabung evaporator melebihi suhu yang sudah ditentukan dan juga data suhu pada Arduino akan ditampilkan pada LCD. Hasil air yang sudah melewati proses distilasi dan menguap ke tabung air bersih.

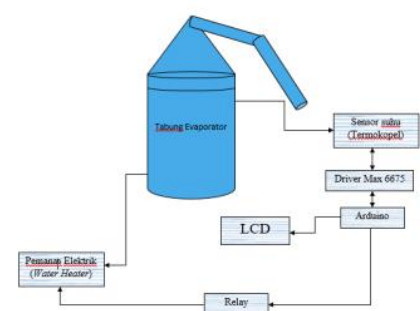

Gambar 12 Blok Diagram Tabung Evaporator

\subsection{Perancangan Water Level Pada Tabung Air Bersih}

Pada gambar 13dibawah ini, perancangan water level berfungsi sebagai indikator hasil air yang sudah di distilasi. Water level akan memberi d.ata ke Arduino dan Arduino akan mengirim data ke LCD.

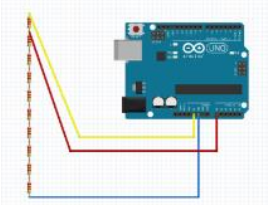

Gambar 13 Skematik Water Level

\section{HASIL PERCOBAAN}

Percobaan ini penulis bertujuan ingin mencari data volume air setelah proses distilasi air laut dan waktu selama proses distilasi berlangsung, dengan input volume air laut yang penulis inginkan dan juga suhu yang telah di tetapkan oleh penulis. Proses distilasi berlangsung relay akan menjaga suhu pada tabung evaporator dengan cara memutus dan menghubungkan tegangan yang tersambung pada pemanas elektrik. 


\section{B. B. Taqwa ${ }^{1 *}$, R. Rosalina ${ }^{2}$, H. Ramza ${ }^{3}$}

Penulis melakukan tiga kali percobaan yaitu, dengan memasukan input volume air 5 liter dan ketetapan suhu pada $102.00^{\circ} \mathrm{C}$, dengan memasukan input volume air 7 liter dan ketetapan suhu pada $102.00^{\circ} \mathrm{C}$. dan juga memasukan input volume air 5 liter dengan ketetapan suhu $92.00^{\circ} \mathrm{C}$. $\mathrm{pH}$ air juga menjadi data acuan penulis ketika proses air laut telah selesai.

\subsection{Percobaan dengan Input Volume Air Laut 5 Liter dan Ketetapan Suhu $102.00{ }^{\circ} \mathrm{C}$}

Pada percobaan kali ini di lakukan pada tanggal 09 Oktober 2020. Input volume air laut pada percobaan kali ini 5 liter dengan ketetapan suhu $102.00^{\circ} \mathrm{C}$.

\begin{tabular}{cc}
$\begin{array}{c}\text { Tabel } 2 \text { Percobaan dengan Input Volume Air Laut } 5 \text { Liter dan } \\
\text { Ketetapan Suhu } \mathbf{1 0 2 . 0 0}^{\circ} \mathbf{C}\end{array}$ \\
\hline \multicolumn{2}{c}{ 09 Oktober 2020 } \\
\hline Jam & $\begin{array}{c}\text { Volume air setelah } \\
\text { distilasi }\end{array}$ \\
\hline $09: 07$ & $0 \mathrm{ml}$ \\
$09: 42$ & $0 \mathrm{ml}$ \\
$10: 18$ & $100 \mathrm{ml}$ \\
$11: 09$ & $200 \mathrm{ml}$ \\
$11: 56$ & $300 \mathrm{ml}$ \\
$12: 50$ & $400 \mathrm{ml}$ \\
$13: 34$ & $500 \mathrm{ml}$ \\
14.03 & $600 \mathrm{ml}$ \\
\hline
\end{tabular}

Pada Percobaan Tabel 2 di atas pada tanggal 09 Oktober 2020 dengan input volume air laut yang akan masuk melewati proses distilasi adalah 5 liter dengan ketetapan suhu $102.00^{\circ} \mathrm{C}$. Pada suhu awal tabung air laut adalah $55.00^{\circ} \mathrm{C}$ pada jam 09:07 volume air setelah distilasi $0 \mathrm{ml}$. Suhu pada tabung evaporator semakin naik, dan mencapai suhu $102.00^{\circ} \mathrm{C}$ pada jam 09:42 hasil pada distilasi air laut 0 $\mathrm{ml}$ dan relay bekerja jika suhu pada tabung evaporator melebihi suhu yang sudah ditetapkan, selisih dari awal suhu mencapai suhu yang di tetapkan $102.00^{\circ} \mathrm{C}$ adalah 35 menit. Pada suhu $101.75^{\circ} \mathrm{C}$ di jam 10:18, volume pada tabung air bersih adalah $100 \mathrm{ml}$, dengan selisih waktu dengan suhu mencapai $102.00^{\circ} \mathrm{C}$ adalah 35 menit. Pada suhu $101.75^{\circ} \mathrm{C}$ di jam 11:09, volume pada tabung air bersih adalah $200 \mathrm{ml}$, dengan selisih waktu dengan volume yang didapati air besih $100 \mathrm{ml}$ adalah 91 menit. Pada suhu $101.50{ }^{\circ} \mathrm{C}$ di jam 11:56, volume pada tabung air bersih adalah $300 \mathrm{ml}$, dengan selisih waktu dengan volume yang didapati air besih $200 \mathrm{ml}$ adalah 47 menit.

Pada suhu $101.75^{\circ} \mathrm{C}$ di jam 12:50, volume pada tabung air bersih adalah $400 \mathrm{ml}$, dengan selisih waktu dengan volume yang didapati air besih $300 \mathrm{ml}$ adalah 94 menit. Pada suhu $101.50{ }^{\circ} \mathrm{C}$ di jam 13:34, volume pada tabung air bersih adalah $500 \mathrm{ml}$, dengan selisih waktu dengan volume yang didapati air besih $400 \mathrm{ml}$ adalah 84 menit. Pada suhu $101.75{ }^{\circ} \mathrm{C}$ di jam 14:03, volume pada tabung air bersih adalah $600 \mathrm{ml}$, dengan selisih waktu dengan volume yang didapati air besih $500 \mathrm{ml}$ adalah 69 menit. Pada jam 14:12 air pada tabung evaporator habis. Pada percobaan ini, proses distilasi air laut membutuhkan waktu 5 jam 5 menit.

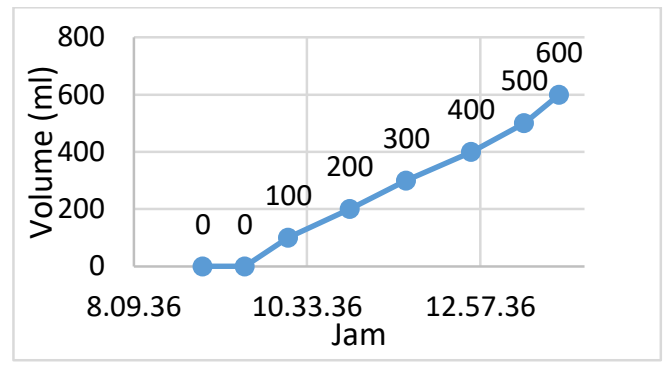

Gambar 14. Grafik Input Volume Air Laut 5 liter dengan Ketetapan Suhu $102.00^{\circ} \mathrm{C}$

\subsection{Percobaan dengan Input Volume Air Laut 7 Liter dan Ketetapan Suhu $102.00^{\circ} \mathrm{C}$.}

Pada percobaan kali ini di lakukan pada tanggal 10 Oktober 2020. Input volume air laut pada percobaan kali ini 7 liter dengan ketetapan suhu $102.00^{\circ} \mathrm{C}$.

Tabel 3 Percobaan dengan Input Volume Air Laut 7 Liter dan Ketetapan Suhu $102.00{ }^{\circ} \mathrm{C}$

\begin{tabular}{lc}
\multicolumn{3}{c}{ Ketetapan Suhu 102.00 ${ }^{\circ}$} \\
\hline Jam & 10 Oktober 2020 \\
\hline $07: 50$ & Volume air setelah distilasi \\
$08: 32$ & $0 \mathrm{ml}$ \\
$09: 17$ & $0 \mathrm{ml}$ \\
$09: 48$ & $100 \mathrm{ml}$ \\
$10: 27$ & $200 \mathrm{ml}$ \\
$11: 30$ & $300 \mathrm{ml}$ \\
$12: 21$ & $400 \mathrm{ml}$ \\
12.56 & $500 \mathrm{ml}$ \\
$13: 05$ & $600 \mathrm{ml}$ \\
\hline
\end{tabular}

Pada percobaan Tabel 3 kedua tanggal 10 Oktober 2020, penulis menggunakan input air laut dengan volume 7 liter dan suhu yang ditetapkan adalah 102.00 ${ }^{\circ} \mathrm{C}$. Pada suhu awal tabung evaporator $31.50{ }^{\circ} \mathrm{C}$ di jam 07:50 volume air setelah distilasi $0 \mathrm{ml}$. suhu pada tabung evaporator semakin naik dan mencapai suhu $102.00{ }^{\circ} \mathrm{C}$ pada jam 08:32 volume air setelah distilasi 0 $\mathrm{ml}$, dengan selisih waktu antara suhu awal 82 menit.

Pada jam 09:17 dengan suhu $101.75^{\circ} \mathrm{C}$ volume setelah distilasi $100 \mathrm{ml}$, dengan selisih waktu antara suhu yang di tetapkan 85 menit. Pada jam 09:48 dengan suhu $101.50{ }^{\circ} \mathrm{C}$ volume setelah distilasi $200 \mathrm{ml}$, dengan selisih waktu antara $100 \mathrm{ml}$ adalah 31 menit. Pada jam 10: 27 dengan suhu $101.75{ }^{\circ} \mathrm{C}$ volume setelah distilasi $300 \mathrm{ml}$, dengan selisih waktu antara $200 \mathrm{ml}$ adalah 79 menit. Pada jam 11:30 dengan suhu $101.75{ }^{\circ} \mathrm{C}$ volume setelah distilasi $400 \mathrm{ml}$, dengan selisih waktu antara 300 ml adalah 103 menit. 


\section{B. B. Taqwa ${ }^{1 *}$, R. Rosalina ${ }^{2}$, H. Ramza ${ }^{3}$}

Pada jam 12:21 dengan suhu $101.75{ }^{\circ} \mathrm{C}$ volume setelah distilasi $500 \mathrm{ml}$, dengan selisih waktu antara $400 \mathrm{ml}$ adalah 91 menit. Pada jam 12.56 dengan suhu $101.50^{\circ} \mathrm{C}$ volume setelah distilasi $600 \mathrm{ml}$, dengan selisih waktu antara $500 \mathrm{ml}$ adalah 35 menit.

Pada jam 13:05 dengan suhu $101.75^{\circ} \mathrm{C}$ volume setelah distilasi $700 \mathrm{ml}$, dengan selisih waktu antara $600 \mathrm{ml}$ adalah 35 menit. Jam $13: 14$ pada suhu $101.75^{\circ} \mathrm{C}$ air laut pada tabung evaporator habis. Total waktu selama distilasi pada percobaan ini adalah 5 jam 55 menit.

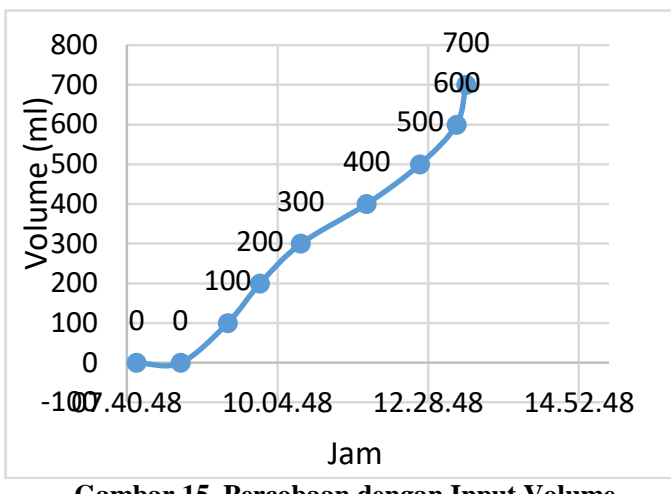

Gambar 15. Percobaan dengan Input Volume Air Laut 7 Liter dan Ketetapan Suhu $102.00^{\circ} \mathrm{C}$

4.3 Percobaan dengan Input Volume Air Laut 5 Liter dan Ketetapan Suhu ${ }^{100.00}{ }^{\circ} \mathrm{C}$

Pada percobaan kali ini di lakukan pada tanggal 22 Oktober 2020. Input volume air laut pada percobaan kali ini 5 liter dengan ketetapan suhu $100.00^{\circ} \mathrm{C}$.

Tabel 4 Percobaan dengan Input Volume Air Laut 5 Liter dan Ketetapan Suhu $100.00^{\circ} \mathrm{C}$

\begin{tabular}{cc}
\hline \multicolumn{2}{c}{ 22 Oktober 2020 } \\
\hline Jam & Volume Air Setelah Distiasi \\
\hline $07: 52$ & $0 \mathrm{ml}$ \\
$08: 41$ & $0 \mathrm{ml}$ \\
$13: 26$ & $100 \mathrm{ml}$ \\
$15: 58$ & $200 \mathrm{ml}$ \\
$18: 15$ & $300 \mathrm{ml}$ \\
\hline
\end{tabular}

Pada percobaan Tabel 4 pada tanggal 22 Oktober 2020 penulis menggunakan input air laut 5 liter dengan ketetapan suhu $100.00^{\circ} \mathrm{C}$. Suhu awal pada tabung evaporator adalah $37.25{ }^{\circ} \mathrm{C}$ pada jam 07:52 volume air setelah distilasi $0 \mathrm{ml}$. Jam 08:41 pada tabung evaporator mencapai suhu 100.00 ${ }^{\circ} \mathrm{C}$ volume air setelah distilasi air laut $0 \mathrm{ml}$, dengan selsih waktu dengan suhu awal 89 menit. Jam 13:26 pada tabung evaporator mencapai suhu $99.75{ }^{\circ} \mathrm{C}$ volume air setelah distilasi air laut $100 \mathrm{ml}$, dengan selisih waktu antara suhu mencapai $99.75^{\circ} \mathrm{C}$ adalah 5 jam 25 menit.

Jam 15:58 pada tabung evaporator mencapai suhu $99.50^{\circ} \mathrm{C}$ volume air setelah distilasi air laut $200 \mathrm{ml}$, dengan selisih waktu antara suhu mencapai $100 \mathrm{ml}$ adalah 2 jam 32 menit. Jam 18:15 dengan suhu $99.75{ }^{\circ} \mathrm{C}$ volume air pada tabung evaporator $300 \mathrm{ml}$, dengan selisih waktu 2 jam 57 menit. Jam 18:40 air pada tabuing evaporator habis. Pada percobaan ini, proses distilasi air laut menghabiskan waktu 11 jam 3 menit.

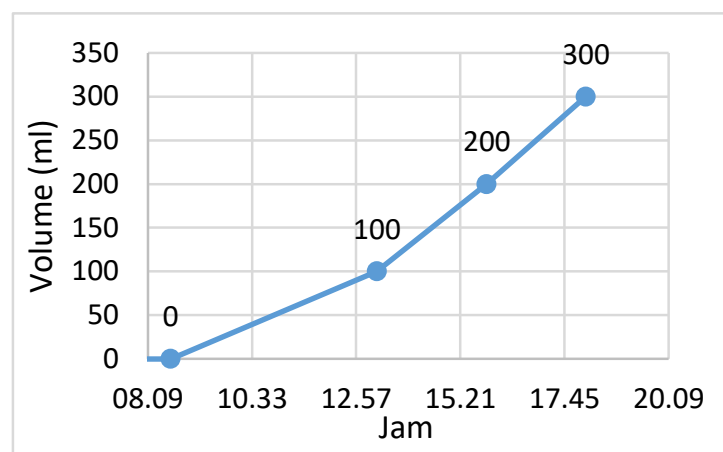

Gambar 16Percobaan dengan Input Volume Air Laut 5 Liter dan Ketetapan Suhu $100.00{ }^{\circ} \mathrm{C}$

\subsection{Percobaan dengan Input Volume Air Laut 7 Liter dan Ketetapan Suhu $100.00^{\circ} \mathrm{C}$}

Pada percobaan kali ini di lakukan pada tanggal 23 Oktober 2020. Input volume air laut pada percobaan kali ini 7 liter dengan ketetapan suhu $100.00^{\circ} \mathrm{C}$.

Tabel 5 Percobaan dengan Input Volume 7 Liter dan Ketetapan Suhu $100.00^{\circ} \mathrm{C}$

\begin{tabular}{cc}
\hline \multicolumn{2}{c}{23 Oktober 2020 } \\
\hline Jam & Volume air setelah distilasi \\
\hline $08: 40$ & $0 \mathrm{ml}$ \\
$09: 43$ & $0 \mathrm{ml}$ \\
$15: 01$ & $100 \mathrm{ml}$ \\
$17: 45$ & $200 \mathrm{ml}$ \\
$20: 46$ & $300 \mathrm{ml}$ \\
$22: 18$ & $400 \mathrm{ml}$ \\
\hline
\end{tabular}

Pada percobaan Tabel 5 pada tanggal 23 Oktober 2020 penulis menggunakan input air laut 7 liter dengan ketetapan suhu $100.00^{\circ} \mathrm{C}$. Suhu awal pada tabung evaporator adala $33.50{ }^{\circ} \mathrm{C}$ pada jam 08:40 volume air setelah distilasi $0 \mathrm{ml}$. Jam 09:43 pada tabung evaporator mencapai suhu 100.00 ${ }^{\circ} \mathrm{C}$ volume air setelah distilasi air laut $0 \mathrm{ml}$, dengan selsih waktu dengan suhu awal 1 jam 3 menit. Jam 15:01 pada tabung evaporator mencapai suhu $99.75{ }^{\circ} \mathrm{C}$ volume air setelah distilasi air laut $100 \mathrm{ml}$, dengan selisih waktu antara suhu mencapai $100.00^{\circ} \mathrm{C}$ adalah 5 jam 58 menit. Jam 17:45 pada tabung evaporator mencapai suhu $99.75^{\circ} \mathrm{C}$ volume air setelah distilasi air laut $200 \mathrm{ml}$, dengan selisih waktu antara suhu mencapai $100 \mathrm{ml}$ adalah 2 jam 44 menit.

Jam 20:46 dengan suhu $99.50{ }^{\circ} \mathrm{C}$ volume air pada tabung evaporator $300 \mathrm{ml}$, dengan selisih waktu 3 jam 1 menit. Jam 22:18 dengan suhu $99.75{ }^{\circ} \mathrm{C}$ volume air pada tabung evaporator $400 \mathrm{ml}$, dengan selisih waktu 2 jam 12 menit. Jam 23:04 air pada tabung evaporator habis. Pada percobaan ini, proses distilasi menghabiskan waktu selama 14 jam 18 menit. 


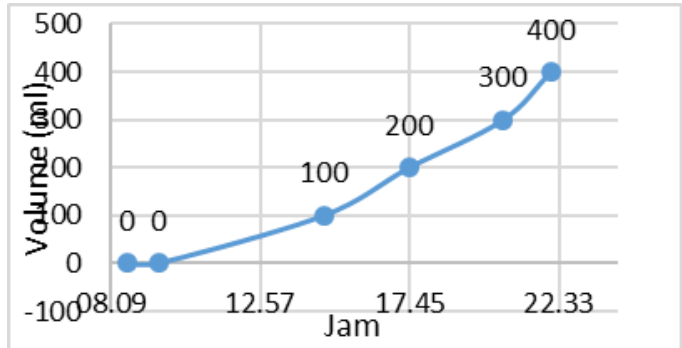

Gambar 17 Percobaan dengan Input Volume 7 Liter dan Ketetapan Suhu $\mathbf{1 0 0 . 0 0}^{\circ}$

4.5 Percobaan dengan Input Volume 5 Liter dan Ketetapan Suhu $92.00^{\circ} \mathrm{C}$

Pada percobaan kali ini di lakukan pada tanggal 11 Oktober 2020. Input volume air laut pada percobaan kali ini 5 liter dengan ketetapan suhu $92.00^{\circ} \mathrm{C}$.

Tabel 6 Percobaan dengan Input Volume 5 Liter dan Ketetapan Suhu $92.00^{\circ} \mathrm{C}$

\begin{tabular}{cc} 
& dan Ketetapan Suhu $\mathbf{9 2 . 0 0}{ }^{\circ} \mathbf{C}$ \\
\hline & 11 Oktober 2020 \\
\hline Jam & Volume air setelah distilasi \\
\hline $08: 51$ & $0 \mathrm{ml}$ \\
$09: 20$ & $0 \mathrm{ml}$ \\
$17: 32$ & $100 \mathrm{ml}$ \\
$19: 58$ & $200 \mathrm{ml}$ \\
\hline
\end{tabular}

Pada percobaan Tabel 4.5 pada tanggal 11 Oktober 2020 penulis menggunakan input air laut 5 liter dengan ketetapan suhu $92.00^{\circ} \mathrm{C}$. Suhu awal pada tabung evaporator adalah $31.25{ }^{\circ} \mathrm{C}$ pada jam 08:51 volume air setelah distilasi $0 \mathrm{ml}$. Jam 09:20 pada tabung evaporator mencapai suhu $92.00{ }^{\circ} \mathrm{C}$ volume air setelah distilasi air laut $0 \mathrm{ml}$, dengan selsih waktu dengan suhu awal 69 menit. Jam 17:32 pada tabung evaporator mencapai suhu $91.50{ }^{\circ} \mathrm{C}$ volume air setelah distilasi air laut $100 \mathrm{ml}$, dengan selisih waktu antara suhu mencapai $92.00{ }^{\circ} \mathrm{C}$ adalah 5 jam 12 menit. Jam 19:58 pada tabung evaporator mencapai suhu $91.50{ }^{\circ} \mathrm{C}$ volume air setelah distilasi air laut $200 \mathrm{ml}$, dengan selisih waktu antara suhu mencapai $100 \mathrm{ml}$ adalah 2 jam 26 menit. Jam 17:23 dengan suhu $91.75{ }^{\circ} \mathrm{C}$ volume air pada tabung evaporator habis. Pada percobaan ini, proses distilasi menghabiskan waktu 11 jam 7 menit.

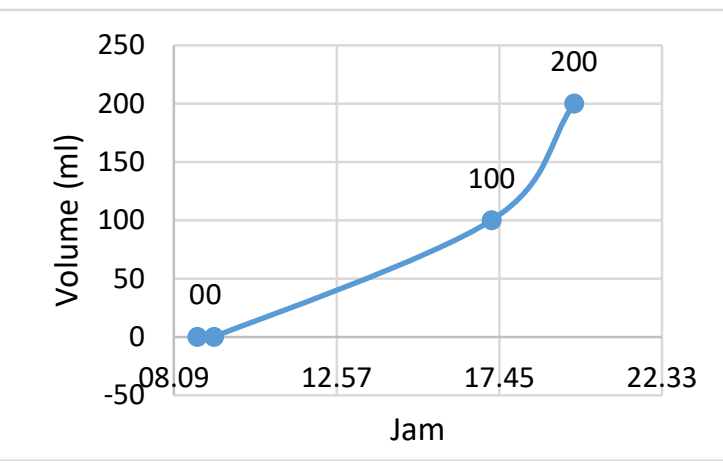

Gambar 17 Percobaan dengan Input Volume 5 Liter dan Ketetapan Suhu $\mathbf{9 2 . 0 0}^{\circ} \mathrm{C}$

\subsection{Percobaan dengan Input Volume 7 Liter dan Ketetapan Suhu $92.00^{\circ} \mathrm{C}$}

Pada percobaan kali ini di lakukan pada tanggal 24 Oktober 2020. Input volume air laut pada percobaan kali ini 5 liter dengan ketetapan suhu $92.00^{\circ} \mathrm{C}$.

\begin{tabular}{cc}
\multicolumn{2}{c}{$\begin{array}{c}\text { Tabel } 7 \text { Percobaan dengan Input Volume } \\
\text { 5 Liter dan Ketetapan Suhu } \mathbf{9 2 . 0 0}{ }^{\circ} \mathbf{C}\end{array}$} \\
\hline \multicolumn{2}{c}{ 24 Oktober 2020} \\
\hline Jam & Volume air setelah distilasi \\
\hline $06: 23$ & $0 \mathrm{ml}$ \\
$07: 35$ & $0 \mathrm{ml}$ \\
$16: 07$ & $100 \mathrm{ml}$ \\
$19: 13$ & $200 \mathrm{ml}$ \\
$21: 10$ & $300 \mathrm{ml}$ \\
\hline
\end{tabular}

Pada percobaan Tabel 4.6 pada tanggal 24 Oktober 2020 penulis menggunakan input air laut 7 liter dengan ketetapan suhu $100.00^{\circ} \mathrm{C}$. Suhu awal pada tabung evaporator adalah $33.50{ }^{\circ} \mathrm{C}$ pada jam $06: 23$ volume air setelah distilasi $0 \mathrm{ml}$. Jam 07:35 pada tabung evaporator mencapai suhu $92.00{ }^{\circ} \mathrm{C}$ volume air setelah distilasi air laut $0 \mathrm{ml}$, dengan selsih waktu dengan suhu awal 1 jam 12 menit.

Jam 13:07 pada tabung evaporator mencapai suhu $91.50{ }^{\circ} \mathrm{C}$ volume air setelah distilasi air laut $100 \mathrm{ml}$, dengan selisih waktu antara suhu mencapai $92.00{ }^{\circ} \mathrm{C}$ adalah 6 jam 12 menit. Jam 16:13 pada tabung evaporator mencapai suhu $91.50^{\circ} \mathrm{C}$ volume air setelah distilasi air laut $200 \mathrm{ml}$, dengan selisih waktu antara suhu mencapai $100 \mathrm{ml}$ adalah 3 jam 6 menit. Jam 18:08 dengan suhu $91.75^{\circ} \mathrm{C}$ volume air pada tabung evaporator $300 \mathrm{ml}$, dengan selisih waktu 2 jam 35 menit. Jam 19:12 air pada tabung evaporator habis. Pada percobaan kali ini, proses distilasi menghabiskan waktu 15 jam 27 menit.

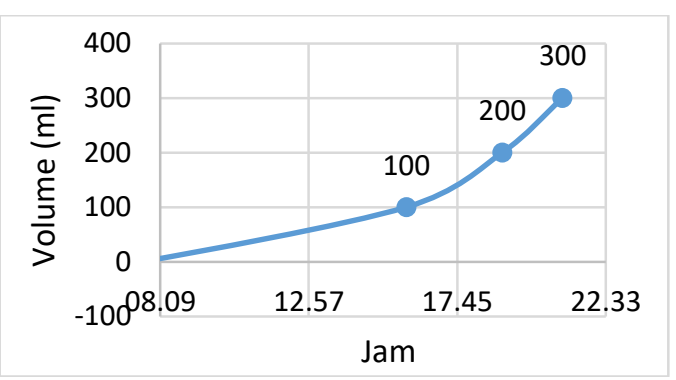

Gambar 18 Percobaan dengan Input Volume 5 Liter dan Ketetapan Suhu $92.00^{\circ} \mathrm{C}$

\subsection{Perhitungan listrik}

Pada percobaan alat proses distilasi air laut ini disesuaikan dengan pemakaian pemanas elektrik dan lama penggunaan alat. Pemanas listrik pada alat proses distilasi memiliki daya 1000 watt. Rumus untuk mencari tariff listrik selama pemakaian alat adalah,

Biaya $=\left(\frac{\text { Daya } x \text { Waktu Pemakaian }}{1000}\right)(k W h) \times$ Tarif Listrik $(k W h$ 
Tabel 8 Perhitungan Listrik Alat Proses Distilasi Air Laut

\begin{tabular}{|c|c|c|c|c|c|}
\hline $\begin{array}{c}\text { Tanggal } \\
\text { Percobaan }\end{array}$ & Heater & Daya & Waktu & $\begin{array}{c}\text { Tarif } \\
\text { Listrik }\end{array}$ & $\begin{array}{c}\text { Biaya } \\
\text { Listrik }\end{array}$ \\
\hline $\begin{array}{c}09 \text { Oktober } \\
2020\end{array}$ & 1 & 1000 & 5.05 & 169 & Rp 853,45 \\
\hline $\begin{array}{l}10 \text { Oktober } \\
2020\end{array}$ & 1 & 1000 & 5.55 & 169 & Rp 937,95 \\
\hline $\begin{array}{l}22 \text { Oktober } \\
2020\end{array}$ & 1 & 1000 & 11.3 & 169 & $\underset{1.909,70}{\mathrm{Rp}}$ \\
\hline $\begin{array}{c}23 \text { Oktober } \\
2020\end{array}$ & 1 & 1000 & 14.18 & 169 & $\begin{array}{c}\mathrm{Rp} \\
2.396,42\end{array}$ \\
\hline $\begin{array}{l}11 \text { Oktober } \\
2020\end{array}$ & 1 & 1000 & 11.07 & 169 & $\underset{1.870,83}{\mathrm{Rp}}$ \\
\hline $\begin{array}{c}24 \text { Oktober } \\
2020\end{array}$ & 1 & 1000 & 15.27 & 169 & $\underset{2.580,06}{\mathrm{Rp}}$ \\
\hline
\end{tabular}

Pada percobaan tabel 8 dengan Volume 5 Liter dan Ketetapan Suhu $102.00^{\circ} \mathrm{C}$ biaya listriknya adalah $\mathrm{Rp}$ 853.45. Percobaan kedua dengan percobaan dengan Volume 7 Liter dan Ketetapan Suhu $102.00^{\circ} \mathrm{C}$ biaya listriknya adalah $\mathrm{Rp}$ 937,95. Pada percobaan ketiga Input dengan volume air laut 5 liter dengan ketetapan suhu $100.00^{\circ} \mathrm{C}$ biaya listriknya sebesar Rp 1.909,70. Pada percobaan keempat dengan volume air laut 7 liter dengan ketetapan suhu $100.00^{\circ} \mathrm{C}$ biaya listriknya sebesar 2.396,42.

Pada percobaan kelima dengan volume 5 Liter dan Ketetapan Suhu $92.00^{\circ} \mathrm{C}$, biaya listriknya sebesar $\mathrm{Rp}$ 1.870,83. Pada percobaan keenam dengan volume 7 liter dengan ketetapan suhu $92.00^{\circ} \mathrm{C}$, biaya listriknya sebesar $\mathrm{Rp}$ $2.580,06$.

\subsection{Percobaan Kelayakan Air}

Pada percobaan kali ini penulis menguji kelayakan air apakah hasil air dari proses distilasi air laut layak dikonsumsi sehari- hari atau tidak. Percobaan dilakukan dengan setiap percobaan yang dilakukan di ukur $\mathrm{pH}$ dan PPM.

\begin{tabular}{ccccc}
\multicolumn{3}{c}{ Tabel 9 Kelayakan Hasil Air Proses Distilasi Air Laut } \\
\hline Suhu Ketetapan & \multicolumn{2}{c}{ Kadar $\mathrm{pH}$} & \multicolumn{2}{c}{ Kadar PPM } \\
\cline { 2 - 5 }$\left({ }^{\circ} \mathrm{C}\right)$ & $5 \mathrm{~L}$ & $7 \mathrm{~L}$ & $5 \mathrm{~L}$ & $7 \mathrm{~L}$ \\
\hline 102 & 7,6 & 7,5 & 43 & 41 \\
100 & 7,3 & 7,5 & 35 & 33 \\
92 & 7,2 & 7,3 & 25 & 21 \\
\hline
\end{tabular}

Berdasarkan tabel 9 didapati hasil $\mathrm{pH}$ air masing- masing sekitar 7, berarti air hasil proses distilasi air laut dikategorikan normal. Pada kadar PPM didapati hasil seperti pada tabel 9 yang mana di bawah dari 50 ppm, yang mana dapat dikategorikan dapat diminum yang mengandung organik. Hasil dari pada tabel 9 diartikan layak dikonsumsi sehari-hari.

\subsection{Pembahasan}

Pada percobaan kali ini, peneliti menguji seberapa besar alat porses distilasi air laut mempunyai nilai efektivitas yang diukur dari hasil percobaan berkala 5 liter dan 7 liter dengan suhu yang sudah ditetapkan masing-masing $102.00^{\circ} \mathrm{C}, 100.00^{\circ} \mathrm{C}$, dan $92.00^{\circ} \mathrm{C}$.

\subsection{Nilai Efektivitas pada Input 5 Liter Volume Air Laut dengan Ketetapan Suhu Masing-Masing $102.00^{\circ} \mathrm{C}, \mathbf{1 0 0 . 0 0}^{\circ} \mathrm{C}, \operatorname{dan} 92.00^{\circ} \mathrm{C}$.}

Pada percobaan kali ini Penulis mengambil grafik dari percobaan masing-masing untuk mengetahui nilai efektivitas pada volume 5 liter yang di ambil dari masing masing percobaan ketetapan suhu. Penulis mengambil grafik dari percobaan masing-masing.

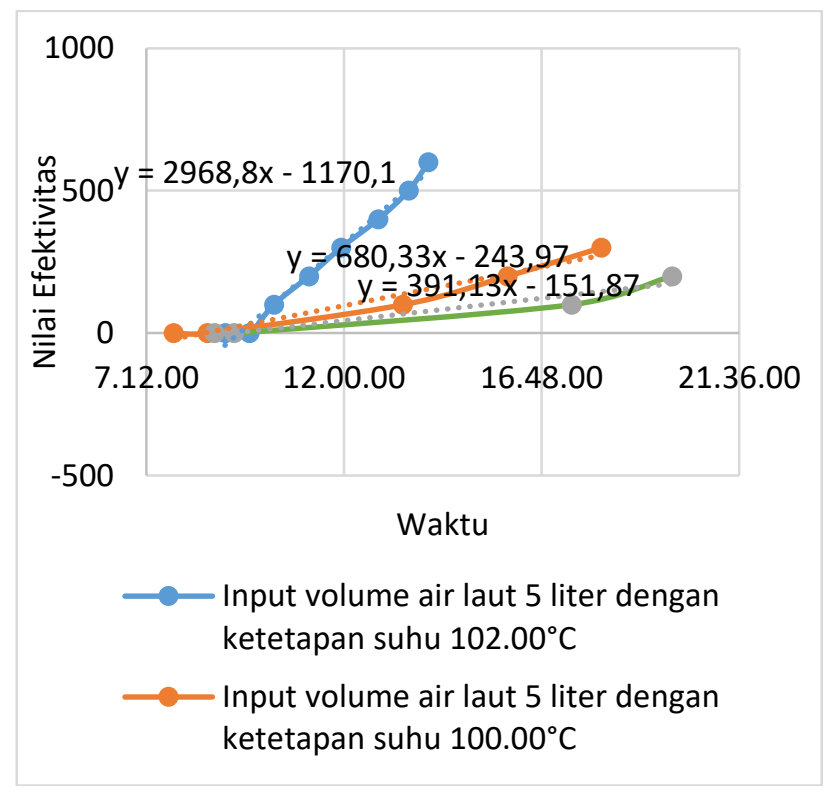
Gambar 19 Grafik Percobaan Efektivitas 5 Liter dengan
Ketetapan Suhu Masing-Masing $102.00{ }^{\circ} \mathrm{C}, \mathbf{1 0 0 . 0 0}^{\circ} \mathrm{C}$, dan 92.00 ${ }^{\circ}$.

Pada gambar 20 grafik di atas didapatkan bahwa dengan input volume 5 liter air laut yang masing-masing percobaan berbeda ketetapan suhunya maka berbeda pula efekitifitasnya. Pada grafik pada tabel 20 yang nilai ketetapan suhu $102.00^{\circ} \mathrm{C}$, dihasilkan volume $600 \mathrm{ml}$ dengan waktu 5 jam 5 menit yang berarti grafik penunujukannya menjulang ke atas dan didapati nilai efektivitasnya $\mathrm{y}=$ 2968.8x - 1170.1.

Pada ketetapan suhu $100.00^{\circ} \mathrm{C}$, gambar grafik 20 menunujukan agak landai karena pada percobaan ini volume yang dihasilkan $300 \mathrm{ml}$ dan menghabiskan waktu 11 jam 3 menit yang mana didapati nilai kefektivitasnya $\mathrm{y}=$ 680.33x - 243.97. Pada ketetapan suhu $92.00^{\circ} \mathrm{C}$, gambar 20 grafik menunjukan landai karena pada percobaan ini volume yang dihasilkan $200 \mathrm{ml}$ dan menghabiskan waktu 11 jam 3 menit yang mana didapati nilai efektivitasnya $\mathrm{y}=$ $391.13 x-151.87$. 
4.11 Nilai Efektivitas pada Input 7 Liter Volume Air Laut dengan Ketetapan Suhu Masing-Masing $102.00^{\circ} \mathrm{C}, \mathbf{1 0 0 . 0 0}^{\circ} \mathrm{C}$, dan $92.00^{\circ} \mathrm{C}$.

Pada percobaan kali ini Penulis mengambil grafik dari Pada percobaan kali ini Penulis mengambil grafik dari percobaan masing-masing untuk mengetahui nilai efektivitas pada volume 7 liter yang di ambil dari masing masing percobaan ketetapan suhu. Penulis mengambil grafik dari percobaan masing-masing.

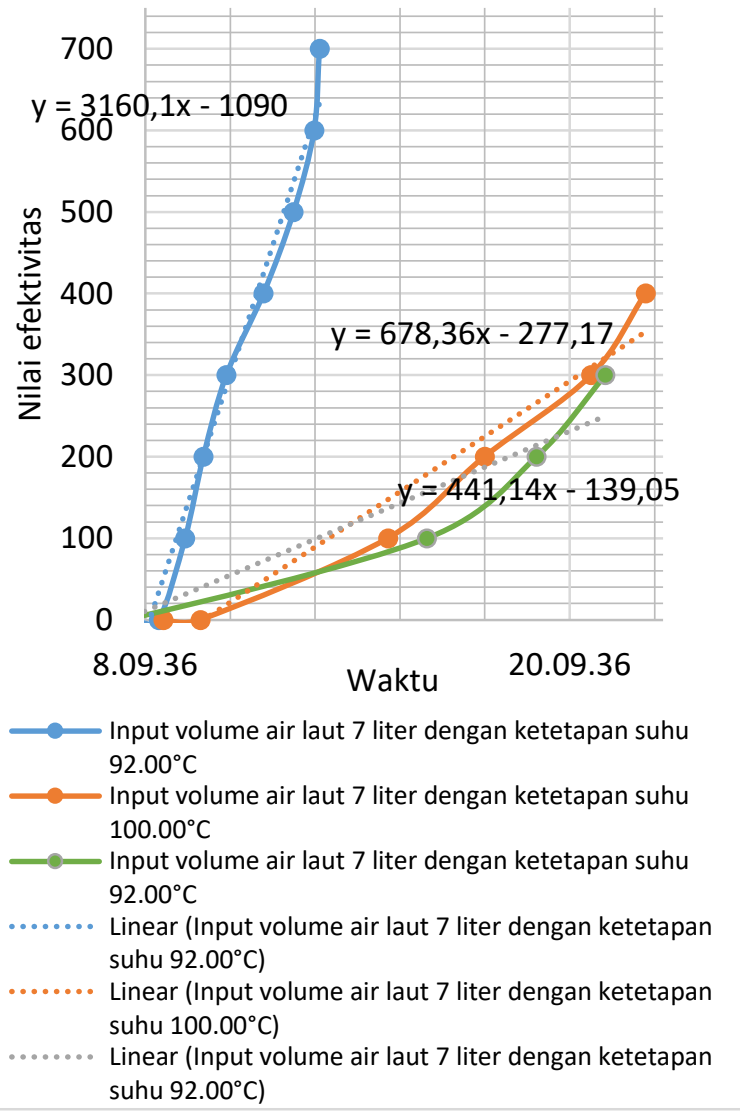

Gambar 20 Grafik Percobaan Efektivitas 7 Liter dengan Ketetapan Suhu Masing-Masing $102.00^{\circ} \mathrm{C}, \mathbf{1 0 0 . 0 0}^{\circ} \mathrm{C}$, dan $92.00^{\circ} \mathrm{C}$.

Pada gambar 21 grafik di atas didapatkan bahwa dengan input volume 5 liter air laut yang masing-masing percobaan berbeda ketetapan suhunya maka berbeda pula efekitifitasnya. Pada grafik pada tabel 21 yang nilai ketetapan suhu $102.00^{\circ} \mathrm{C}$, dihasilkan volume $700 \mathrm{ml}$ dengan 5 jam 55 menit. yang berarti grafik penunujukannya menjulang ke atas dan didapati nilai efektivitasnya $\mathrm{y}=$ 3160.1x - 1090.

Pada ketetapan suhu $100.00^{\circ} \mathrm{C}$, gambar grafik 21 menunujukan agak landai karena pada percobaan ini volume yang dihasilkan $400 \mathrm{ml}$ dan menghabiskan waktu 14 jam 18 menit yang mana didapati nilai kefektivitasnya y $=678.36 \mathrm{x}-277.17$. Pada ketetapan suhu $92.00^{\circ} \mathrm{C}$, gambar 21 grafik menunjukan landai karena pada percobaan ini volume yang dihasilkan $200 \mathrm{ml}$ dan menghabiskan waktu
15 jam 27 menit yang mana didapati nilai efektivitasnya $\mathrm{y}=$ $441.14 x-139.05$.

\subsection{Perhitungan Regresi Sederhana}

Berdasarkan tabel 4. 1 dan 4. 2 diatas untuk mendapat nilai efektivitasnya dengan menggunakan persamaan regresi linear sederhana untuk setiap percobaan ketatapan. Persamaan regresi dapat ditentukan efektivitas proses distilasi air laut dengan menggunakan persamaan dibawah ini,

$$
\eta=\frac{\Delta X}{\Delta Y}=\frac{d y}{d x}
$$

Nilai efektivitas untuk setiap perocobaan dapat dihasilkan seperti pada tabel 4.3 dibawah ini. Pada tabel ini juga disusun berdasarkan volume masukan air laut sebelum proses distilasi sebesar 5 liter dan 7 Liter.

Tabel 10 Penentuan Efektivitas Berdasarkan Regresi Linear Sederhana

\begin{tabular}{|c|c|c|c|c|}
\hline \multirow{2}{*}{$\begin{array}{c}\text { Suhu } \\
\text { ketetapan } \\
\left({ }^{\circ} \mathrm{C}\right)\end{array}$} & \multicolumn{2}{|c|}{ Persamaan regresi } & \multicolumn{2}{|c|}{ Nilai efektivitas } \\
\hline & $\begin{array}{c}5 \\
\text { (Liter) } \\
\end{array}$ & $\begin{array}{c}7 \\
\text { (Liter) } \\
\end{array}$ & $\begin{array}{c}5 \\
\text { (Liter) } \\
\end{array}$ & $\begin{array}{c}7 \\
\text { (Liter) } \\
\end{array}$ \\
\hline 102.00 & $\begin{array}{c}\mathrm{y}=2968.8 \mathrm{x}- \\
1170.1\end{array}$ & $\begin{array}{c}y=3160.1 x \\
-1090\end{array}$ & 2968.8 & 3160.1 \\
\hline 100.00 & $\begin{array}{c}y=680.33 x- \\
243.97\end{array}$ & $\begin{array}{c}y=678.36 x- \\
277.17\end{array}$ & 680.33 & 678.36 \\
\hline 92.00 & $\begin{array}{c}y=391.13 x- \\
151.87\end{array}$ & $\begin{array}{c}\mathrm{y}=441.14 \mathrm{x}- \\
139.05\end{array}$ & 391.13 & 441.14 \\
\hline
\end{tabular}

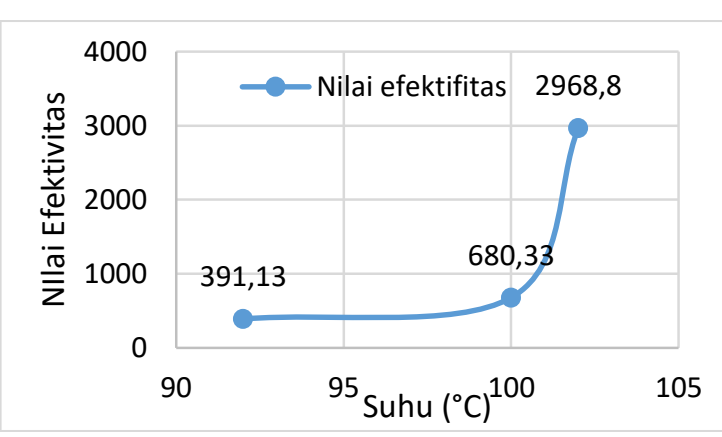

Gambar 21 Grafik Efektivitas 5 Liter dengan Masing-Masing Ketetapan Suhu

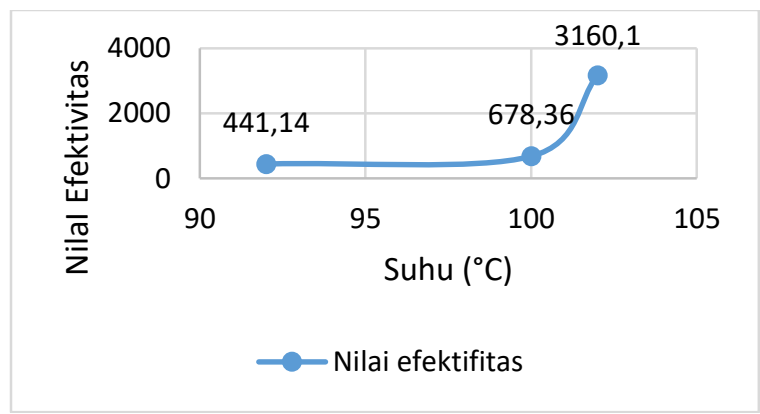

Gambar 22 Grafik Efektivitas 7 Liter Dengan Masing-Masing Ketetapan Suhu 


\section{KESIMPULAN}

Berdasarkan dari hasil percobaan dan pengambilan data pada perancangan alat proses distilasi air laut menggunakan pemanas elektrik,maka dapat disimpulkan :

1. Input volume air laut mempengaruhi hasil volume air setelah proses distilasi air laut, semakin besar volume input air laut air yang dihasikan distilasi semakin banyak.

2. Semakin rendah suhu pada tabung evaporator maka semakin kurang tekanan pada tabung evaporator dan proses distilasi menjadi mengahbiskan waktu lebih lama, dikarenakan uap pada tabung evaporator sedikit yang dapat naik pada selang tabung evaporator mengakibatkan volume air pada tabung air bersih menjadi sedikit.

3. Kadar air hasil porses distilasi air laut memiliki ph air sekitar 7,5 dan memiliki kadar sekitar 35 ppm. Ukuran kadar air tersebut air dari hasil porses distilasi berarti air dari hasil proses distilasi layak dikonsumsi sehari hari.

4. Pemanas elektrik efektif untuk proses distilasi air laut, dikarenakan suhu pada tabung evaporator yang stabil.

5. Volume 5 Liter dan Ketetapan Suhu $102.00^{\circ} \mathrm{C}$ biaya listriknya adalah $\mathrm{Rp} 853.45$ dan volume 7 liter dengan ketetapan suhu $92.00^{\circ} \mathrm{C}$, biaya listriknya sebesar Rp $2.580,06$.

\section{KEPUSTAKAAN}

Azis, M. A., \& Fajaryati, N. (2018). Reosquido Desalinasi Metode Evaporasi Dengan Ultraviolet Berbasis Mikrokontroller. 3(November), 38-47. https://doi.org/10.21831/elinvo.v3i2.20885

Bachtiar ilman mochamad. (2018). prototype monitoring dan kontrol suhu pada proses pengasapan karet RSS (Ribbed Smoked Sheet). Digital Reposity Universitas Jember, 8.

ERFAN, A. M. (2017). Rancang Bangun Destilator Air Laut Tenaga Surya, SKRIPSI. In Central Library Of Maulana Malik Ibrahim State Islamic University Of Malang.

Idawati Supu, Baso Usman, Selviani Basri, S. (2016). Pengaruh Suhu Terhadap Perpindahan Panas Pada Material Yang Berbeda. Jurnal Dinamika, Vol. 07. N(12), 62. https://doi.org/10.1128/AAC.03728-14

JauhariArifin, Leni Natalia Zulita, H. (2016). Perancangan Murottal Otomatis Menggunakan Mikrokontroller Arduino Mega 2560. Jurnal Media Infotama, 12(ISSN 1858 - 2680), 89.

Khairunnas, \& Gusman, M. (2018). Analisis Pengaruh Parameter Konduktivitas , Resistivitas dan TDS Terhadap Salinitas Air Tanah Dangkal pada Kondisi Air Laut Pasang dan Air Laut Surut di Daerah Pesisir Pantai Kota Padang. Jurnal Bina Tambang, 3(4), 1751-1760.
Saleh, M., \& Haryanti, M. (2017). Rancang Bangun Sistem Keamanan Rumah Menggunakan Relay, ISSN : 2086 - 9479. Jurnal Teknik Elektro, 8(3), 181-186.

Zulfian Azmi, Saniman, I. (2016). Sistem Penghitung Ph Air Pada Tambak Ikan Berbasis Mikrokontroller. Sistem Penghitung PH Air Pada Tambak Ikan Berbasis Mikrokontroller, 15, 102. 